\title{
Noumenal Technology: Reflections on the Incredible Tininess of $\mathrm{Nano}^{1}$
}

\begin{abstract}
Alfred Nordmann
In Joachim Schummer and Davis Baird (eds.) Nanotechnology Challenges: Implications for Philosophy, Ethics and Society, Singapore: World Scientific Publishing, 2006, pp. 49-72; originally in Techné, 8:3, 2005, pp. 3-23
\end{abstract}

Noumena are distinct from phenomena. While the latter are the things as they appear to us and as we experience them, the noumena are the philosophically infamous and mysterious things-inthemselves. ${ }^{2}$ The "noumenal technology" referred to in the title of this paper would therefore appear to be a contradiction in terms: Technology is a human creation that involves human knowledge and serves human needs; this firmly roots it in phenomena and it appears absurd to speak of technology that exists beyond human perception and experience among the things-in-themselves. The noumenal world is nature uncomprehended, unexperienced, and uncontrolled; it is nature in the sense of uncultivated, uncanny otherness. By speaking of "noumenal technology" this paper argues that some technologies are retreating from human access, perception, and control, and thus assume the character of this uncanny otherness.

Three seemingly disparate reflections prepare the formulation of this thesis, and the remaining sections work to establish at least its plausibility.

\section{THE EMPEROR'S NEW GUITAR}

Under the heading "US-researchers play nano-guitar" the following brief notice appeared not long ago in a German newspaper:

\footnotetext{
${ }^{1}$ I would like to thank Michael Hauskeller for provoking this paper, Jean-Pierre Dupuy, George Khushf, Joseph Pitt, Joachim Schummer, Alexei Grinbaum, and Pieter Vermaas for commentary and criticism.

2 Among Kant scholars, there is some debate as to whether noumena and the things in themselves should actually be equated. Whether or not there is a subtle distinction to be made here, does not affect the following discussion.
} 
US-researchers struck the smallest guitar string in the world: The journal Nature reports that a nanocarbontube only a few millionth of a millimeter wide vibrates with an inaudibly high frequency. (Frankfurter Rundschau September 16, 2004)

Too small to be seen, too high-pitched to be heard, this is clearly not much of a guitar. Indeed, one might wonder why anyone would call it a guitar in the first place. In fact, the Nature editorial does not refer to a guitar at all but likens the observed effects to "the strings of a violin" (Cleland 2004). ${ }^{3}$ Since this does little to clarify matters, the article explains that the resonance frequency of the nanotubes can be tuned - and both, the notions of resonance and of tuning suggest the functional similarity to a stringed musical instrument. The analogy can now be extended to say that the functionality may lead to devices or instruments. Researchers may well begin to play on these instruments, though not to produce music but, for example, to amplify the instrument's informational state and thus to make it an "electronic detector-one that can 'hear' its own motions." The editorial concludes by expressing the hope that "[f]uture efforts may add multistringed instruments to the present device - and perhaps, in time, arrive at a full symphony orchestra" (Cleland 2004).

The nano-guitar adds further evidence to Joachim Schummer's thesis about the aesthetic origin of molecular nanotechnology. He argues that the technical functionality of molecules was suggested by a certain way of looking at molecules within supramolecular chemistry, where molecular structures became associated with artifacts like baskets, rotors, or chains (Schummer forthcoming). Assuming the position of the newspaper reader, however, we might go on and probe a little more deeply what it means to imagine as a familiar instrument like a violin or electric guitar something that is utterly remote to our senses, namely a carbon nanotube which is suspended between two gold electrodes and tuned by the variation of gate voltages.

\section{MASTERY OF NATURE}

Francis Bacon's famous dictum that "knowledge is power" ties the advance of theoretical understanding to the expansion of experimental control. ${ }^{4}$ We know that we know when we can bring things about on the basis of our knowledge. It is worth asking whether the inverse holds and whether the advance of technical control is tied to representations of what we do. Do we have mastery of nature only to the extent that this mastery is rehearsed and reproduced in thought?

\footnotetext{
${ }^{3}$ Cleland's editorial comments regard a finding by Sazonosa et al. 2004. The authors of that paper refer in their abstract to "guitarstring-like oscillation modes of doubly clamped nanotube oscillators." Neither paper includes the now-popular picture of the "nanoguitar."

4 Though Bacon did not coin the phrase, he has become powerfully associated with it as the founder of modern science by Merchant (1980), Böhme (1993), Schäfer (1993), compare Soble (1997).
} 
In recent years, the philosophy of instrument and experiment has pressed this issue by showing that experiments and technical constructions can have a life of their own, that is, independent of scientific theory (for example, Baird 2004). Accordingly, the general claim that technical control is accompanied by conceptual representations must be distinguished from the more specific, untenable claim that technical control consists in the application of theoretical knowledge. Once this distinction is kept in mind, the relation between power and knowledge can be formulated in a more innocuous and intuitive manner: Technology involves humanly initiated causal processes. Some have very detailed knowledge of how such processes unfold. Others imagine only the turn of a switch and a resulting action. Yet others have a largely intuitive and physical mastery of, say, their bicycle and equate the causality of stopping, turning, or adapting gear with the causal powers of their own, technically extended bodies. In all these cases, technical mastery is attended by representations of how this power is exercised. ${ }^{5}$ Indeed, it appears inconceivable to say that we technically control nature without possessing at the same time some conceptual image - no matter how impoverished - of the causality that is implied by the very notion of control. This raises the question whether the nano-guitar or other technologies are such that we fail to form such a conceptual image even though we must do so in order to assert responsibility and control.

It is important to distinguish the case where we must, but fail to imagine the workings of a technology, from the familiar case where we need not do so and where, in fact, we do so only in a most rudimentary way. This familiar case goes under the name of "black-boxing" and was described as early as 1919 by Max Weber in "Science as a Vocation":

Excepting physicists who know the subject, those of us who take a streetcar have no idea how it sets itself in motion. We do not need to know this. It is enough to "count" on the behavior of the streetcar, we orient our actions accordingly; but we know nothing of how one constructs a streetcar so that it moves. Savages know their tools incomparably better...Increasing intellectualization rationalization therefore do not imply increasing general knowledge of one's conditions of life. It implies something else, namely knowledge of or faith in the fact that, if only one wanted to, one could find out any time, thus that in principle there are no secret, incalculable forces entering in, that instead - in principle - the things can be mastered through calculation (Weber 1988, 593ff.).

Weber's case of the streetcar refers to a most impoverished but still existing connection between technical control and causal representation. In cases like these we represent our technical interventions in the world only as a generic causal relation between input and output: When I flip this switch, some action will commence or conclude even if I know nothing about the mechanism through which this is effected.

\footnotetext{
${ }^{5}$ Heidegger (1977) offers an account according to which technical control presupposes a causal picture of the world, one in which actions either poetically bring forth what lies dormant or instrumentally exploit a scheme of means-end relations.
} 
However, the nano-guitar or genetically modified foods, ambient intelligence, nanoparticulate sensors, and pervasive large technical systems raise the question whether technical control is decoupled far more fundamentally even from generic representations. In these cases, it might not help to look up in a book how the technology operates because all the explanations and illustrations in the world do not yield perspicuity. Indeed, these technologies may well become more unfathomable when we are asked to imagine their unimaginably intricate workings that lie beyond the reach of our senses. Also, for these technologies the notions of use or of a user and thus of control are meaningless to the innumerable non-users who find themselves conscripted into their technological networks. Technological interventions, like the nano-guitar, might be operating in the background, unknown and unknowable to us. They therefore do not become objects of experience - and what is no object of experience remains unrepresented and does not prompt the formation of a conceptual image of its working. To the extent that they remain in the unconsidered and unconceptualized background of our actions and lives, these technologies are much like brute and uncomprehended nature-instead of knowing them, we merely know of them. Their looming presence and potential efficacy does not appear as an extension of our freedom or our will, but as a mere constraint, even perhaps as a threat. Where technical and intellectual control come apart, the humanly induced workings of technology no longer signify mastery of nature but take on the character of nature itself.

This would further suggest that the novelty of these technologies is not the Technisierung der Natur (nature taking on the character of technology) which may be as old as agriculture but, instead, the Naturalisierung der Technik (technology taken on the character of nature). ${ }^{6}$

\section{(Mis)UNDERSTANDING KANT}

In all our attempts to understand the philosophy of Immanuel Kant, we inevitably encounter the question regarding the "thing-in-itself." This question can be answered in a roughly correct and in a woefully incorrect manner. By speaking of "noumenal technologies," this paper will be flirting with the incorrect one. - According to the roughly correct account, the things-in-themselves are nature unrepresented in experience-if it were possible to speak of this nature at all. ${ }^{7}$ We do not and

\footnotetext{
${ }^{6}$ For the notion of Technisierung der Natur (nature taking on the character of technology) see, for example, Ropohl (1991, pp. 70ff.) Here, nature is considered in terms of machines or literally rendered machine-like in order to assimilate nature to culture and to the spheres of knowledge and control. In contrast, Naturalisierung der Technik (technology naturalized) considers nature an engineer for the purposes of conceiving technology as natural. The latter strategy was identified, for example, in Nordmann (2004, pp. 52f.)

7 Compare Kant's Critique of Pure Reason, especially pp. A 236-260 (B 294-315) where "noumenon" is defined as a problematic concept, that is, as a concept which contains no contradiction and is yet empty in that there is no means by which its objective reality could be ascertained (A 254, B 310, compare A 252). There is no contradiction in assuming that there are "things in themselves" of which we only experience (phenomenal) appearances. But there is also no means to ascertain the objective reality of anything except by the way in which it appears to us. To posit the "thing in itself" as beyond and in some sense prior to human experience (as brute nature) involves no contradiction but also does not allow us to speak of the "thing in itself" as if we could know anything about it, including that it exists.
} 
cannot know the things-in-themselves or nature "as it is" (with the one tenuous exception, perhaps, of our own nature as free, intellectual beings). This unknowability of the noumena or things-inthemselves can be described as a limit to theoretical understanding. Put positively, it represents the characteristic effort of modernity to push back the alien and uncanny otherness of nature. How things appear to us as phenomena in experience is already structured by the mind, already subject to mathematization and intellectual control. As opposed to brute nature, the phenomena are already civilized.

Now, the woefully inadequate account goes something like this: If you want to know what noumena or things-in-themselves are, consider things like atoms or molecules. After all, we cannot directly experience them and yet our phenomenal world of experience is composed of them. This interpretation is obviously incorrect because we formulate and test scientific theories about atoms and molecules. These are therefore objects of knowledge and it was precisely for all objects of knowledge that Kant showed how we constitute them as phenomena in time and space, as subject to causality, etc. As far as science is concerned, atoms and molecules are definitely no things-inthemselves that are unstructured by our minds. As objects of knowledge they come with, they are part and parcel of our theoretical representations. ${ }^{8}$ But perhaps, as far as technology is concerned and when the bond between understanding and technical control is severed, atoms and molecules might as well be things-in-themselves. For all practical purposes, that is what they are. In what follows, the nano-guitar and other examples will be recruited to suggest that nanotechnologies, in particular, are thought to act in ways that remain, quite literally, inaccessible and in a size-regime that despite all our scientific theories remains unknowable. ${ }^{9}$

\section{NOUMENAL TECHNOLOGY}

Taken together, the preceding remarks suggest the thesis or at least explain the title of this paper: Noumenal technologies arise where the link between representation and control is broken, that is, when we successfully create artifacts and perhaps a technical agency whose presence and action are inscrutable to us and, in effect, indistinguishable from the presence and action of the natural processes that serve as an unconsidered background and framework of our lives.

\footnotetext{
${ }^{8}$ One cannot argue, for example, that chemical change has a "deep structure" which is noumenal and that chemistry as a science should attend to this structure, see Stein 2004, especially note 1. If something can be conceived as a possible object of scientific experience, it is not noumenal. To be sure, the fact that process is not now the subject of chemical thought may reflect the conditions of possibility for chemical experience - whatever is meant by "process" may not be intelligible, especially if it involves a notion of transmutation that violates conservation principles. If this were the case, there can be no knowledge of such processes, scientific or otherwise, and the notion of chemical process would then serve, at best, to elucidate the limits of chemical knowledge.

9 It will become clear, however, that only a small and perhaps insignificant part of actual nanotechnology research concerns technologies that act at the nanoscale. The argument does not apply to the more familiar applications where nanostructured materials serve as a substrate or medium for macroscopic action - as in the case of a macroscopic desktop computer that includes nanostructured components, for example.
} 
In order to substantiate this thesis, it needs to be shown that with the nano-guitar and numerous associated technologies, technical intervention eludes imaginative or conceptual grasp. Indeed, Günther Anders has shown something very much like this half a century ago for nuclear technology. ${ }^{10}$

As engineers, at least as engineers of nuclear weapons, we have become omnipotent - an expression that is little more than a metaphor. But as intellectual beings we do not measure up to this omnipotence of ours. In other words: by way of our technology we have gotten ourselves into a situation in which we can no longer conceive (vorstellen) what we can produce (herstellen) and do (anstellen). What does this discrepancy between conception (Vorstellung) and production (Herstellung) signify? It signifies that in a new and terrible sense we "know no longer what we do"; that we have reached the limit of responsibility. For to "assume responsibility" is nothing other than to admit to one's deeds, the effects of which one had conceived (vorgestellt) in advance and had really been able to imagine (vorstellen) (Anders 1972, 73f; see also 33-40, 88f, 96-99). ${ }^{11}$

Anders reflects the incommensurability or absolute disproportionality between the scale of human action and the scale at which its effects unfold. In one size regime occurs a perfectly conceivable technical malfunction or a human reaction to a perceived threat, in quite another size regime there is the perfectly predictable, yet utterly inconceivable end of humankind. The nanoguitar, genetically modified foods, or pervasive technical system present a different kind of inconceivability, one that still needs to be characterized.

Rather than serve as an instrument for deliberate action in the world, such noumenal technology recedes into the uncanny otherness of nature and resists our attempts to make it an object of experience and knowledge. Its elusive character can be characterized, perhaps, in reference to Gerhard Gamm's conception of technology as a medium that structures human action without being present in experience as a structuring device—somewhat like blood in our bodies or money in our economies (Gamm 2000). ${ }^{12}$ As such, this technology is knowledge-based and yet no tool or instrumental application of scientific knowledge. By the same token, this technology does not prefigure the scientific manner of recruiting calculable effects of nature (compare Heidegger 1977).

\footnotetext{
${ }^{10}$ I would like to thank Jean-Pierre Dupuy for drawing my attention to this.

${ }^{11}$ Anders developed the distinction between Vorstellen and Herstellen in Anders (1956). He repeatedly placed it in the context of Kant's philosophy: Kant's critique has shown how our intellectual capacities are limited but the possible effects of nuclear weapons cannot be accommodated within the limits of the human condition but transgress or exceed it altogether (see Anders 1972, pp. 33f., $38,73)$.

12 See also Bensaude-Vincent (2004). Gamm, to be sure, takes his thesis about technology as a medium to be more general than suggested here. With Bensaude-Vincent I would like not only to distinguish the peculiar characteristics of such noumenal technology but trace how different technologies come to be no more than an intractable medium for human action. Pace Bensaude-Vincent, I insist on "noumenal" as opposed to "immaterial" technology because - unlike rituals, bureaucratic procedures, or social codes - the "nano"-dimensions of nanotechnology are not thought to be immaterial but, more fundamentally, fail to become material by failing to become an object of experience at all.
} 
Instead, the mutual dependence of science and technology, of knowing and acting comes asunder in noumenal technology and Max Weber's story of progressive rationalization unravels.

By definition, science involves objects of knowledge and experience. To the extent that we see the world through the glasses of science, we remain — as Kant would say - the lawgivers of nature and consider phenomena in their causal or structural contexts. This is certainly true also of nanoscience and its understanding of nanoscale phenomena. In contrast, noumenal artifacts like the nano-guitar turn out to be in essential respects not even objects of science, even though they were discovered, controlled, and explained by scientists and engineers. Where technical artifacts are no objects of experience, the scientific and technical rationalization of the world and the disenchantment of nature give way to a celebration of magic and enchantment. Naturalized technology is a mere medium for action, so deeply embedded that it eludes reflection or deliberate use, let alone rejection. As technical control outstrips intellectual control, our progressively expanded technical reach might thus prove regressive as regards the mastery not only of nature but of our own destiny. ${ }^{13}$

Genetically modified foods serve as a paradigm for this and, depending on how it develops, so may nanotechnology. They begin as purposeful interventions in nature (e.g., pesticide resistance) but their effects cannot ordinarily be observed or tracked even as they propagate through human bodies. Rather than reduce anxiety by assimilating nature to culture and by rationalizing the world through technology, such noumenal technology heightens anxiety. It does so by implicating us in a pervasive technical environment that is just as uncanny as is nature with its imperceptible germs, viruses, or bacteria on the one hand, its disruptive and haphazard earth-quakes, lightning-strikes, or volcanic eruptions on the other. These technologies enter the sphere of rationality only when we assume the mostly fictitious vantage-point of a user whose judgement is not based on immediate physical experience but on statistically mediated experiences of benefits relative to costs or risks. The farmers, for example, who choose to plant genetically modified crops may experience an increase in yield and they can thus articulate a rational justification of their choice. But even these farmers, of course, have no experience of the genetic modification when they are cooking and ingesting their crops, and even they may find the presence of this unexperienced modification uncanny.

This regressive rather than progressive aspect of noumenal technology in regard to the mastery of nature is of a different character entirely than the familiar problem of not being able to imagine

\footnotetext{
${ }^{13}$ Compare the discussion of Bill Joy's "Why the future doesn't need us" (Joy 2000) in Nordmann $(2004,50)$.
} 
all the consequences of some technical intervention. Indeed, even where we have technical control with attendant representations, inadvertent effects may well get ahead of our imaginative abilitiesas happens in the case of the "sorcerer's apprentice" and whenever the effects of our actions get "out of hand." Here the limits of imagination consist in a computational inability to think through easily representable but highly complex pathways and interactions. In contrast, noumenal technologies and phenomenal (scientific) representations are incommensurable from the beginning since essential features of the technology cannot enter into phenomenal representations at all. Again, Günther Anders was perhaps the first to carefully distinguish the practical inconceivability of the infinitely long chain of effects that follows upon any human action, from the absolute inconceivability of the infinite magnitude of the single, perfectly predictable, and immediate effect of a nuclear attack (see Anders 1972, p. 34). The noumenal technologies discussed here involve a similar incommensurability. It results from the fact that the indefinitely near- or medium-term agency of certain technologies is shielded from our sensory modalities. To the seismic movements of nature that may eventually produce an earth-quake, human engineering is adding further causal processes that operate behind our backs with possibly catastrophic consequences.

\section{The Absolute SMALlness OF NANO}

The elaboration so far of the thesis has shown that its plausibility hinges on the claim that the nanoguitar is not an object of science, even though it was presented, discussed, and even though its construction and workings were explained by scientists in the journal Nature. This apparently paradoxical claim needs to be elucidated and, ideally, justified. Here is the argument in a nut-shell: As a nanotechnological artifact the nano-guitar is essentially small. Its "incredible tininess" and ability to perform defined functions at the nanometer scale is its very point and apparently the point of much (though by no means all) nanotechnology. ${ }^{14}$ If something is so small that we cannot imagine its size and if yet we feel that we must imagine its size in order to grasp its essential feature as a nanotechnological artifact, we will be attempting and failing to grasp something noumenal, namely how small or large something really is. In contrast, like everything noumenal, absolute size is never a feature of objects of science or knowledge. These objects are constituted and represented as they phenomenally appear to us and our measuring apparatus, that is, as relatively large or small, as measuring so much on some scale, as comparatively smaller or larger than something else. In

\footnotetext{
14 "The Incredible Tininess of Nano" is the heading of a section in IWGN $(1999,3)$. I am taking this heading literally: The tininess of nano is not just amazing but incredible - impossible to be known, believed, or imagined. Of course, the brochure goes on to ask of us what cannot be done, namely that we imagine this incredible tininess.
} 
other words, we can know and imagine a great deal about the nano-guitar, but we cannot know at least one of its essential features as a nanotechnological artifact. The nano-guitar therefore demonstrates simultaneously the expansion of technical control and the limits of human understanding, and because of this it is an object of technology that is not at the same time an object of science.

What is represented in the journal Nature is the nano-guitar as a phenomenon, namely as it appears to scientists by way of their representational tools and within their traditions and conventions of representing states of matter and motion. The readers are told how the guitar is constructed and how it works, they can learn to understand the relation of the parts to the whole, and they can refer its interesting properties to a rather general theoretical account of atoms and molecules. In other words, the readers of Nature will know quite a bit about the nano-guitar and in respect to this knowledge, the nano-guitar is clearly an object of scientific, though not ordinary experience. There is one feature of the nano-guitar, however, which is not represented to the scientists and which alone makes it a specifically nanotechnological device, and that is its size. We see in images and print a perfectly macroscopic representation that appeals to our sensory modalities. For the most part this image of the world at the nanoscale is to be taken quite literally: in this world, if you produce an electrical impulse here, you will observe some oscillation there. But like all scientific articles, this one does not (and need not) tell us how small this world really is. We are simply informed, for example, that 1 centimeter in the image before our eyes corresponds to 1 nanometer. Here, there is no literalness but a translation of sorts - the nanoworld has been scaled up for the purposes of human perception and understanding. As long as the scientists realize that nanometers are greater than angstroms and smaller than micrometers, that they are considering molecular rather than atomic or astronomic scale, all is well. Scientists are not required to correct for this scaling effect or to somehow subtract in their minds the magnification that was provided by their instruments.

Accordingly, it is not just a lay audience that has to deal with the incredible tininess of nano but also nanoscientists who learn to manipulate individual atoms, including the creator of nanoscience's most conspicuous accomplishment regarding the positioning of atoms at will. Don Eigler used 35 xenon atoms to spell the letters "IBM" with all three letters spanning less than 3 nanometers, and yet he declares fifteen years later: "If you can imagine anything that's a billionth of anything else, you are way of ahead of me" (Eigler 2004). ${ }^{15}$ Put another way, as far as Don Eigler is concerned,

${ }^{15}$ Don Eigler during a presentation at the conference Images of Science, Amsterdam, December 7, 2004. 
the grouping of xenon atoms measures precisely 2 to 3 nanometers across and at the same time is unimaginably small. The first half of this statement refers to relative size as measured at the nanometer scale, the second half of this statement refers to absolute size and how small something really is.

Eigler's nanotechnological achievement draws attention to an incommensurability that goes entirely unnoticed in science and that does not require our attention in regard to most technology. While a scientifically trained intelligence can imagine the world at the nanoscale, it cannot and need not imagine the length of a nanometer. For science, it is not important and perhaps even an absurd undertaking to imagine the length of a nanometer. In this respect, the "problem" of imagining the length of a nanometer is no different from trying to imagine the length of a meter.

Indeed, it would be quite absurd to assume that to the question "how long is a meter?" there should be an answer in terms of absolute size. Clearly, the meter is a perfectly arbitrary unit and, as such, the best answer provides a mere definition in terms of some non-deformable physical units. It has been an interest of science to provide the terms for such a definition. Also, it is of interest to science that there is a reliable standard of measurement. Beyond that, to ask about the length of a meter is not a scientific question. Not long ago, the questioner would have been referred simply to the "standard meter" in Paris - the length of a meter was defined by the length of that object which served as the international standard. One way or another, the scientific definition involves only relative size, either relative to certain physical operations or to the standard object in Paris. And if one wanted to how long a meter was in terms of human experience, the approximate answer would refer to the human being and the gesture that a meter is about so-and-so long relative to our body in space.

The nanometer is not so defined. There is no "standard nanometer" on display in some vault that provides visual comparison, and there is no gesture indicating that it is roughly so-and-so small. Since the nanometer is a billionth of a meter, this is no problem for science. The size of nanoscale objects is perfectly secure relative to other size scales. But the scientific definition does not satisfy the demand for another, more intuitive grasp of how long a nanometer is. Since even scientists cannot imagine the billionth of anything else, we apparently need to find a way of imagining the nanometer in a way that is not relative to the meter and that substitutes for the absence of any physical relation to human gestures or sensory modalities. Since the length of the nanometer and the relation of a billionth to a whole are beyond the realm of appearances, this amounts to a demand for an intuitive grasp or absolute knowledge of how long a nanometer really is. This demand is given expression in countless introductory presentations and publications of nanotechnology. Those that 
are addressed to scientific peers and those that reach out to a general audience usually begin with more or less impressive, more or less desperate attempts to illustrate how long a nanometer is.

Any request to know what is noumenal or is a property of the things as they are themselves must, by necessity, fail. This holds true also for the request to illustrate and imagine how long a nanometer really is. According to Kant, objects of experience are constituted not only in time and space or the framework of causality but also in terms of magnitude and quantity. As Kant shows especially for infinitesimals, this means that we do not apprehend size as such and how large or small things are in and of themselves (compare Kant 1997, A166ff.). Instead, infinitesimals are represented in a continuum of intensities and effects and thus only in so far as they contribute to human experience. It would be nonsensical to imagine infinitesimals as such or independent of the calculus. Extending Kant's argument, Ludwig Wittgenstein tells us that it would be a similar mistake to take "meter" or "nanometer" for anything but grammatical. ${ }^{16}$ We use these terms to relate things to one another but they have no natures or properties of their own. It would be nonsensical, therefore, to ask how small or large a nanometer is, especially in the absence of any physical rituals or gestures that can serve as symbolic substitutes. What we have, instead, are only the rituals of taking us to the limits of our imagination: "To see a nanometer would be like seeing a postage-stamp from half way across the earth"- which says no more or less than that we cannot do it, that we can neither see nor imagine it. And yet we attempt again and again to imagine the unimaginable, running up against the limits of comprehension. Take this famous anthologized reflection on the large and the small from Kenneth Ford's 1958 introduction to The World of Elementary Particles:

On the submicroscopic frontier of science (as well as on the cosmological frontier) man has proceeded so far away from the familiar scale of the world encompassed by his senses, that he must make a real effort of the imagination to relate these new frontiers to the ordinary world... One of the best ways to try to visualize the very great or the very small is by analogy. For example, to picture the nucleus, whose size is about 10-4 to $10-5$ of the size of an atom, one may imagine the atom expanded to, say, 10,000 feet (104 feet) or nearly two miles. This is about the length of a runway at a large air terminal such as New York International Airport. A fraction 10-4 of this is one foot, or about the diameter of a basketball. A fraction 10-5 is ten times smaller, or about the diameter of a golf ball. A golf ball in the middle of New York International Airport is about as lonely as the proton

\footnotetext{
16 Wittgenstein (1997, remark 50): "There is one thing of which one can say neither that it is one meter long, nor that it is not one meter long, and that is the standard meter in Paris - But this is, of course, not to ascribe any extraordinary property to it, but only to mark its peculiar role in the language-game of measuring with a meter-rule." - To ask how long a meter is would be akin to asking what "being" is. The verb "to be" serves the grammatical purpose of predication, the terms "meter" and "nanometer" belong to the grammar of measuring, that is, of establishing commensurability among things within a given or among different size regimes.
} 
at the center of a hydrogen atom. The basketball would correspond to a heavy nucleus such as uranium (Ford 1991, 18 \& 21f.). ${ }^{17}$

Ford sets out to relate the ordinary to the extreme. This gesture is repeated again and again in the context, for example, of nanotechnology. The relation of 1 nanometer to 1 millimeter, we are told, is like the relation of the distance between New York and Boston to the distance between earth and sun. ${ }^{18}$ These analogies present relative magnitudes and succeed at communicating the loneliness of the golf ball in the middle of today's John F. Kennedy Airport in New York. They help us imagine the world at the atomic or molecular scales, a bit like helping people imagine a foreign country or exotic culture. At the same time these analogies strain and fail to acquaint us with the size of these worlds, their distance from us. Ford exemplifies this when he develops his airport-analogy further and thereby exposes its absurdity:

To arrive at the number of atoms in a cubic centimeter of water (a few drops), first cover the earth with airports, one against the other. Then go up a mile or so and build another solid layer of airports. Do this 100 million times (Ford 1991, 22).

Of course, to imagine our solar system filled up with airports is just as impossible as imagining the number of atoms (all 1016 of them) in a cubic centimeter of water. It also does not help to be told that "if the airport-construction rate were one million each second, the job could have been finished in the known lifetime of the universe (something over 10 billion years)." All these descriptions say the same thing, namely that we cannot imagine these magnitudes or sizes. All scientific knowledge of relative sizes, all technical control does not yield a sense of absolute size, except to say that this or that is "incredibly small."

There is nothing surprising about this failure from a Kantian point of view. What is all the more surprising, therefore, is that we keep trying. Kenneth Ford demands that we "must make a real effort of the imagination to relate these new frontiers to the ordinary world"-why must we?

\section{INTRACTABLE AGENCY}

For the purposes of scientific understanding we do not ordinarily need to represent the size of things -indeed, science probes from within the limits of theoretical understanding and thereby fosters a sense of curiosity and wonder at that which remains unexplained: It is thought to be marvelous even

\footnotetext{
${ }^{17}$ Similarly, it has been suggested that we can imagine a billionth $\left(10^{-9}\right)$ of something else because our experience ranges across $10^{9}$ orders of magnitude from millimeters $\left(10^{-3}\right)$ to 1000 kilometers $\left(10^{6}\right)$. However, even if we could therefore imagine the relation of 1 millimeter to 1000 kilometers (along the lines of imagining a basketball in JFK airport), we could not therefore transfer that imagined relation to the different relation of one nanometer to a meter.

${ }^{18}$ See the brochure Große Chancen im Nanokosmos - Nanotechnologie in Hessen, 2004 (the brochure takes Frankfurt-Kassel as the distance of reference).
} 
that all the mechanisms identified by science are actually taking place in and around us. ${ }^{19}$ We arrive at these moments of wonder when we run up against the limits of what we can imagine. And where this is not marvelous, we can safely refrain from imaging or imagining it. (So, you don't think that it is marvelous that your body is host to millions and millions of incredibly tiny parasites? Don't imagine it then!) Science aims for explanations of interesting perceived regularities, and only the most zealous of scientific realists care whether the unobservables that occur in these explanations correspond to anything real. ${ }^{20}$ In daily life and for purposes for acting successfully in the world, there is no need for complete scientific understanding. This holds also for the probe microscopist who understands the theories of probe microscopy, who moves, even feels individual atoms, but who does not and cannot imagine the smallness of those atoms.

In contrast, we are obliged to form representations of our deliberate actions in the world. Where humans act purposefully, these actions are set off from the unconsidered or black-boxed background environment in which these actions unfold. Whether one thinks of technology as applied science or of science as applied technology, technology is purposeful intervention in the world. We therefore ought to develop a representation, no matter how impoverished, of how the technology works. If we fail to do this, this is a failure not only of imagination but also of morality or responsibility. Günther Anders' work is an indictment of just such failure:

The reach of our responsibility extends as far as the immediate and mediate effects of our actions, our omissions, or our deeds. At least we should try to extend it this far and to assume the magnitude of that which we bring about in the world...Today's "malum" is essentially different from that which has dominated the European tradition, namely the Christian conception of "evil." ...What makes us bad is that as agents we do not measure up to the products of our deeds...The gap is therefore not that between mind and flesh but between product and mind. Example: We can produce the bomb. But we appear to be incapable of imagining what we have become as owners of our products and what we can do and have already done as their owners...This difference is unique in history, and thus unique also in the history of ethics...Due to this being a failure of the imagination, what is "weak" here is the "mind" (Anders 1972, 34-36). ${ }^{21}$

\footnotetext{
${ }^{19}$ Philosophical expressions of this wonder include Kant's introduction to the Critique of the Power of Judgement and Wittgenstein's "not how the world is, is the mystical, but that it is" (Wittgenstein 1922, remark 6.44).

${ }^{20}$ For science and the search for explanatory accounts, it is heuristically useful to assume their real existence. In the course of scientific research, the unobservables become real for all practical purposes of experimentation and instrumentation. But this is true, of course, also of "magical" explanations: If I tell myself that the room has been cleaned by fairies, I assume - of course - that they must really exist since otherwise they could not have performed such a tangible feat.

${ }^{21}$ The novelty of this ethical situation is therefore that it is not the flesh that is weak: "the element of 'nature' that up to now always contributed to a definition of the 'malum' drops out of the picture."
} 
In the case of absolutely disproportionate effects ${ }^{22}$ and in the case of technological agency absolutely below (or above) thresholds of human perception and imagination, to keep up with the effects of one's actions involves the effort to imagine the magnitude of things. Where we must engage in this effort and must by necessity fail, we are confronted with noumenal technology. While the case of nuclear arm signifies the abandonment of the effort and thus a moral failing from the very start, the case of nanotechnology is characterized by the persistent pursuit of the unattainable goal to imagine the unimaginable; it thus expresses a moral ambition to take responsibility beyond the human capacity to responsibly track the consequences of technical intervention. ${ }^{23}$

As we saw, for purposes of scientific understanding there is no imperative to imagine the size of things. For the purposes of taking responsibility for technical interventions, this depends upon the specific character of the technology and whether or not it is noumenal, engaging us in an impossible feat of the imagination. And this specific character is determined in part by our beliefs regarding the causal agency of the technology.

Desktop computers, for example, are clearly not noumenal even though we cannot represent to ourselves the speed and complexity of operations, let alone the site or spatial and temporal extension of a particular inferential step. We can black-box these particulars and are left with a device that relates macroscopic inputs to macroscopic outputs. In contrast, ambient intelligence, distributed or ubiquitous computing may well become a noumenal technology as this technology creates a quasi-natural, though now "intelligent" environment that structures human action without transparency and individual control. In this case, when we black-box the unimaginable we are left with nothing, but a nothing that somehow acts upon us. Whether radios, cellphones, or fluoridized drinking water are noumenal technologies depends entirely on whether one believes that fluor is an "active ingredient" or that radio waves produce environmental effects. Regarding the radio, for example, we are told and for the most part believe that it is controlled by its switch, that its use is closely coupled to our representations of how to manipulate power and volume, and how to seek out stations. At the same time most people hold that the pervasiveness of radio waves serves only as a passive medium that enables the tansmission of signal, and therefore we do not ordinarily imagine these waves along with the macroscopic device that is subject to our control. What defines opponents of cell-phones or of fluoridization is that they view these same technologies as being noumenal. They insist on the need to imagine unimaginable effects and are therefore prone to

\footnotetext{
22 "End of the Comparative. [...] but what is supplied transcends our needs, it consists of things that we cannot desire; it is absolutely too big" (Anders 1972, 99).

${ }^{23}$ This moral ambition finds expression also through early engagement with ethical, social and legal aspects of nanotechnology.
} 
discern a vaguely generalized danger which blends in with and contaminates the background effects of nature itself (water, air, soil). ${ }^{24}$ For them, these pervasive technical interventions change the things-in-themselves, the world not as we know it but where we rely on it unknowingly. This view is reenforced rather than weakened by the fact that we have no sensory experience of these pervasive changes. ${ }^{25}$

This same ambiguity applies to genetically modified foods as the paradigm case for noumenal technology. It is the paradigm case because the technical intervention remains essentially inconspicuous to human senses as well as natural selection. The genetic modification may produce visible as well as invisible phenotypic traits, and these phenotypic traits whither away or become consumed. However, the genetic modification may also persist and continue to act as it passes through our bodies to some untraceable place in the environment. Here, there is no represented proportionality between intervention and effect. Largely due to the smallness of the intervention, the effect is thought to escape our attention and control, meandering on indefinitely, perhaps producing a surprising large effect when and where we least expect it. ${ }^{26}$ Finally, little reassurance comes from reading up on genetic engineering. The more we learn to understand and even admire its technical capabilities, the less transparent the world becomes for the individual consumer of genetically modified foods and the harder to maintain a sense of ownership, empowerment, responsibility, and control. Genetically modified organisms appear uncanny because they operate like nature itself. We can learn how they work, in principle, but we cannot know for any particular genetic modification where, when, and for how long it acts. All the while, however, it is easy to understand why it is that not everyone defines genetically modified foods as an uncanny, noumenal technology that necessarily implicates us in a failure to responsibly track its workings. Many scientists deny, after all, that the genetic modification should be considered biologically active. If its action exhausts itself and terminates in a single phenotype that is otherwise a plant or animal like all others, there is no need to imagine or take responsibility for the modification. In that case, we would simply take responsibility for creating the macroscopic phenotype and thereby remain within the bounds of phenomenal technology.

\footnotetext{
${ }^{24}$ See Todd Haynes's 1999 film [Safe] as an excellent analytic case study of the perceived uncanniness of such and similar technical systems.

${ }^{25} \mathrm{I}$ am here focusing on smallness but it is worthwhile to extend the argument to large and even just largish technologies. (To be sure, ambient computing or radio technology should be considered not simply for the invisible smallness of their physical implementation but also as large technical systems.) For example, should we consider as an example of noumenal technology the fully automated climate control of an office building, if only because it cannot be surveyed or controlled by individual users?

26 This description may not be true to GMOs as we know them. But it captures why this technology is thought by many to be so uncanny.
} 
Similarly, while the effects of a nuclear worst case scenario exceed by far our imaginative capacities, the "normal working" of nuclear technology is not necessarily uncanny. Though we cannot imagine the size of the nuclei of uranium and plutonium, nuclear weapons or reactors are perfectly macroscopic parts of our ordinary world of experience, operated by switches, interfaced through output devices and monitors, relying on a lot of scientifically described, though for the most part black-boxed knowledge of physical mechanisms. As with our desk-top computers, it is irrelevant for questions of responsibility and control just how big or small the smallest components of a nuclear plant or nuclear weapon are. Significantly, however, the most troubling or uncanny aspects of nuclear technology concern the possibility that it might revert to quasi-natural conditions. First among these is the fear of accidental nuclear war as complex systems begin to "act on their own.” This further amplifies the gap between the smallness of the occasion and the unfathomable magnitude of the effect (see Anders 1972, 89). Related to this is the fear of a decision-maker gone mad or the fear of radioactivity as an invisible, yet persistent and pervasive source of environmental contamination.

The discussion so far leaves quite open whether or to what extent nanotechnology will assume the character of noumenal technology. Nanostructured surfaces, material properties, or components in larger devices do not amount to noumenal technologies. When we black-box the incredible tininess of nano we are left with a sufficiently rich conception of how these operate and what it means to take responsibility for their mostly mundane effects. Freestanding nano- to microscale devices such as sensors and distributed components of networked computers are far more likely candidates for noumenal technologies, depending also on whether or not other technologies will allow us ultimately to detect, monitor, and track these devices. Of course, any device with biological properties, such as artificial bacteria for environmental clean-up can be considered noumenal, as would the legendary assemblers and nanobots of whom hardly anybody believes as of yet that they will actually come to pass.

\section{THe MEANings OF FAILURE}

By way of conclusion, it is now possible to identify the deeper significance of the apparently pointless attempts to illustrate again and again the smallness of a nanometer.

From a theoretical point of view, atoms and molecules are phenomena. Indeed, theories are the instruments by which we learn to know things that we cannot know as they are by and of themselves. With the help of theory, science makes images of things, stabilizes them in experiments, 
and creates models to exhibit them. The deliberate use of theory serves to remind scientists that they are creating certain kinds of pictures; it marks these pictures as aides to the imagination. From the point of view of theory, then, it is as a matter of course that these pictures stay within the bounds of imagination and do not convey any true reality of absolute size or the like. The repeated failure of visualization or illustration thus serves as a meaningful reminder of the reliance on scientific theory to establish patterns of relatedness among phenomena. Accordingly, that we cannot imagine the size of molecules is no problem at all: The hapless stories about the incredible tininess of nano underscore that the business of science is to relate things to one another and not to grasp an absolute reality. By dramatizing inconceivability, science highlights the unbridgable difference between noumena and represented phenomena and sides emphatically with the latter.

From the technological point of view, however, these hapless stories have a different meaning in that they strain to accomplish something that needs to be accomplished even where we lack the theoretical and imaginative resources to do so. It is a virtue of theory that it marks the impossibility of moving from scientific representations and how we imagine things to reality as such. Technical interventions, however, engage reality. The moral ambition to keep up in thought with the reach and workings of our technical interventions does not respect limits of knowledge if the interventions themselves reach beyond these limits. The ritual of attempting to illustrate the size of a nanometer thus serves as the constant reminder of an insoluble dilemma. ${ }^{27}$ It is an expression of the moral ambition to take responsibility for nanotechnogy, and its failure demonstrates that some technologies systematically outpace our moral ambition. The exhibition of our failure of imagination thus dramatizes meaningfully the challenge and moral demand to reintegrate noumenal technology within the spheres of reason, responsibility, and control.

It is therefore not at all pointless to try what cannot be done. The ritual of repeatedly failing to imagine the smallness of a nanometer reveals the noumenal character of at least some envisioned nanotechnologies. Such "freestanding" nanotechnologies that are thought to act below the thresholds of perception and responsibility, provoke a mixture of abhorrence, awe, and fear that does not fit into the calculus of rationality. One of our oldest and perhaps deepest fear is the fear of

\footnotetext{
${ }^{27}$ It would be far too simplistic to introduce a variation on the Kantian theme of phenomena vs. noumena by associating on the one hand science with nature and the deterministic representation of phenomena, on the other hand technology with freedom and the expansion of our action as free, rational and responsible (noumenal) beings in the world. This move interprets "noumena" primarily in terms of human freedom (rather than in regard to unknowable things in themselves as limits of knowledge). The insoluble dilemma would thus be associated with the Kantian dilemma that we are free only as noumenal but causally determined as phenomenal beings. If we were to follow this suggestion, noumenal technology would be technology unadulterated. This contrasts starkly with my suggestion, however, that noumenal technology is regressive and tends to diminish human autonomy in that it withdraws from the mastery of nature by giving technology the character of uncomprehended nature.
} 
brute, arational nature that has not been cultivated, rationalized, tamed, domesticated. ${ }^{28}$ If an advance in technical control produces a type of technology that eludes sensory perception and human responsibility, this technology turns out to be regressive in that it casts us back into a state of nature. We cannot trust a noumenal technology. In order to earn our trust the various nanotechnologies will have to move beyond the incredible tininess of nano to become credibly integrated with human experience.

\section{CONTACT}

\section{Alfred Nordmann}

Professor of Philosophy

Technische Universität Darmstadt

Residenzschloss, 64283 Darmstadt, Germany

nordmann@phil.tu-darmstadt.de

\section{REFERENCES}

Anders,G. 1956. Die Antiquiertheit des Menschen. München: Beck.

. 1972. Endzeit und Zeitende: Gedanken über die atomare Situation. München: Beck.

Baird, D. 2004. Thing Knowledge: A Philosophy of Scientific Instruments. Berkeley: University of California Press.

Bensaude-Vincent, B. 2004. Se libérer de la matière?Fantasmes autour des nouvelles technologies. Paris: Institut national de la recherche agronomique.

Böhme, G. 1993. Am Ende des Baconschen Zeitalters: Studien zur Wissenschaftsentwicklung. Frankfurt: Suhrkamp.

Cleland, A.N. 2004. “Carbon Nanotubes Tune Up.” Nature 431 (September 16), 251-252.

Eigler, D. presentation at the conference Images of Science, Amsterdam, December 7, 2004.

Ford, K. W. 1991. "The Large and the Small." In Timothy Ferris (ed.), The World Treasury of Physics, Astronomy, and Mathematics, Boston: Little, Brown.

Gamm, G. 2000. “Technik als Medium.” In Nicht Nichts, Frankfurt: Suhrkamp, pp. 275-287.

\footnotetext{
${ }^{28}$ Baird (2004) and the history of nanotechnology remind us that these four terms should not be equated: by stabilizing phenomena through intuitive knowledge and control of system behaviors technology can "tame" nature without therefore "rationalizing" it. Just to the extent that this is true, however, we are confronted with the problems described in this paper. Indeed, the demand that noumenal technologies be integrated with human experience is premised on the notion that sensory experience and a "feeling" for the technical intervention are sufficient to place the technology into a framework of deliberate and responsible human action.
} 
Heidegger, M. 1977. The Question Concerning Technology, and Other Essays. New York: Harper \& Row.

IWGN (Interagency Working Group on Nanoscience, Engineering and Technology) 1999. Nanotechnology-Shaping the World Atom by Atom. Washington: National Science and Technology Council.

Joy, B. 2000. "Why the Future Doesn't Need Us." Wired (April 2000).

Kant, I. 1997. Critique of Pure Reason. Paul Guyer and Allen Wood (translators and eds.) Cambridge: Cambridge University Press.

. 2000. Critique of the Power of Judgment. Paul Guyer (translator and ed.) Cambridge: Cambridge University Press.

Merchant, C. 1980. The Death of Nature: Women, Ecology, and the Scientific Revolution. San Francisco: Harper \& Row.

Nordmann, A. 2004. "Nanotechnology's Worldview: New Space for Old Cosmologies." IEEE Technology and Society 23:4.

Ropohl, G. 1991. Technologische Aufklärung: Beiträge zur Technikphilosophie. Frankfurt: Suhrkamp.

Sazonosa, V. et al. 2004. "A Tunable Carbon Nanotube Electromechanical Oscillator." Nature 431 (September 16), 284-287.

Schäfer, L. 1993. Das Bacon-Projekt: Von der Erkenntnis, Nutzung und Schonung der Natur. Frankfurt: Suhrkamp.

Schummer, J. (forthcoming). "Gestalt Switch in Molecular Image Perception: The Aesthetic Origin of Molecular Nanotechnology in Supramolecular Chemistry.” Foundations of Chemistry.

Soble, A. 1997. "In Defense of Bacon." In Noretta Koertge, ed. A House Built on Sand: Exposing Postmodernist Myths about Science. Oxford: Oxford University Press, 195-215.

Stein, R. 2004. "Towards a Process Philosophy of Chemistry." Hyle: International Journal for Philosophy of Chemistry, 10:1, 5-22.

Weber, M. 1988. Gesammelte Aufsätze zur Wissenschaftslehre. Tübingen: J.C.B. Mohr.

Wittgenstein, L. 1922. Tracatus Logico-Philosophicus. London: Routledge and Kegan. 1997. Philosophical Investigations. Oxford: Blackwell. 